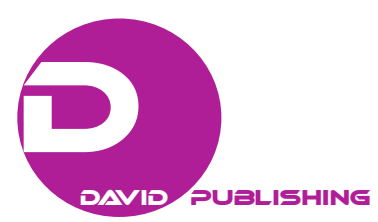

\title{
About the Satisfaction of the Students Attending the Health area Academic Courses of the University of Bari
}

\author{
Angela Maria D’Uggento, \\ Dipartimento di Scienze economiche e metodi matematici, Università degli Studi di Bari. \\ Fabio Manca, Claudia Marin \\ Dipartimento di Scienze della formazione, psicologia, comunicazione, Università degli Studi di Bari
}

\section{Introduction}

In the last decade, the world of academia has faced a period of strong/severe resource constraints/reduction. At the same time, there has been an increasing interest of the Ministry of Research (MIUR) in designing methods to evaluate University performance in order to rank efficient Universities and to reduce potential inefficiencies, so providing the administration authorities with measures that may be used for an optimal resources allocation. With this increasing interest in University performance, a wide academic debate has emerged about the models and measures adopted, based on several quantitative measures of inputs that, sometimes, have been borrowed from the Italian Health organizational model, much more consolidated in its experience. We cite, for all, the students evaluation in terms of standard cost within the resources allocation model introduced last year, and the "customers" satisfaction measurement, whose main goal is to provide an independent system of regular evaluation of student satisfaction and of the University teaching quality.

The aim of this paper is to deal with the students opinion about the quality of teaching, as perceived as "users" while attending their academic courses in the health area. We agree with the statement that the high quality of healthcare services provided to the community depends also on the main factor, the human capital involved in supplying them. In Italy, the academic courses belonging to the health area provide the access to a limited number of students who passed a hard selection. This rule was introduced by the law n.264/1999 to harmonize the Italian University system to the European one in order to guarantee the high quality of students higher education in this field. And that quality of the education, according to the law, depended on the places in the classrooms, on the equipment and scientific laboratories for teaching; on the teaching staff and technical personnel; on the assistance and tutoring service, on the apprenticeships and places available in laboratories and classrooms equipped for practical, on the presence of technical-practical and laboratory activities.

For the Government, that is the main donor for Italian Universities, the level of student satisfaction is of great importance to evaluate the quality of their courses. It is actually measured by different points of view as quality of teachers, teaching materials and logistical support.

The law n.370/1999 states that Italian Universities have to systematically carry out a survey on the satisfaction of "teaching" of their students; this survey is named Opinione degli studenti . Recently, the National Agency of Evaluation (ANVUR) has been entrusted to oversee the related processes. Since 2013, the University of Bari, like the other Universities, has adopted the ANVUR guidelines. 


\section{Data and Methods}

According to the last ANVUR release of the survey, the Universities have to administer three questionnaires: two for students, respectively with more or less than $50 \%$ percent of lessons attendance while the remaining one is for the teacher. Moreover, the Universities should carry out the on line survey after $75 \%$ of lessons held or, at least, when the student is booking for the exam.

The questionnaire number 1 is the most complete because it has to be filled by the students with more than $50 \%$ percent of lessons attendance (Table 1); it is composed by eleven questions grouped into three sections: the first one focuses on the subject, the second on the teacher and the teaching services while the last one concerns the student's interest for the subject. The questionnaire number 3, being addressed to those students who have less than $50 \%$ percent of lessons attendance, shows the same composition, except for questions from 5 to 10 which need the attendance of the lessons to be answered. In order to avoid duplications, we show only the complete student questionnaire specifying that the second has an identical content except for the section "teaching". An important innovation is the presence of 9 suggestions that the student can choose, in addition to the questions. This part contains precious information for the improvement of the quality of teaching and will be deeply analyzed in this paper.

Table 1

ANVUR students' questionnaire

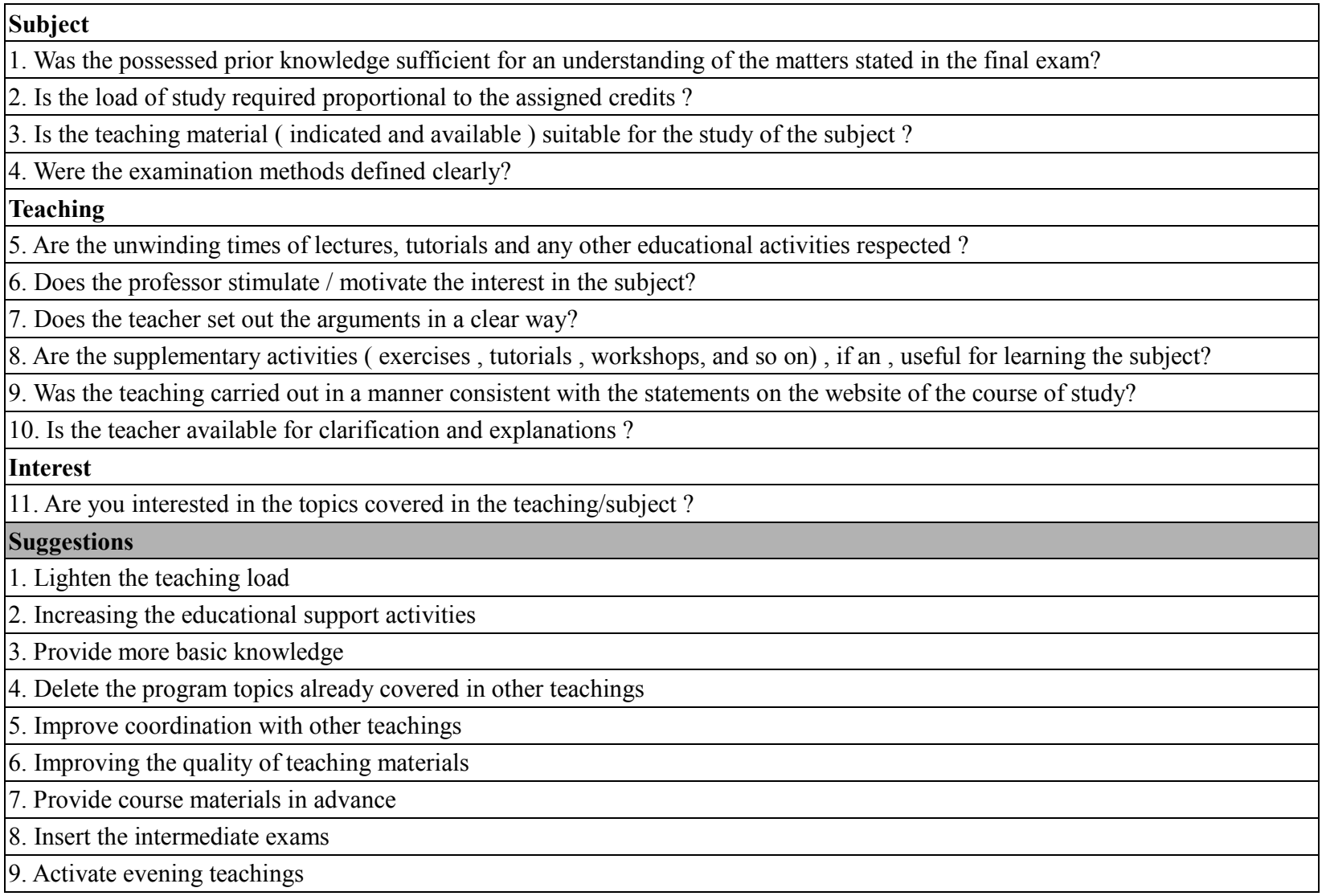

As above said, the questionnaire number 2 has to be filled by the teacher and contains questions aimed at measuring his perception of quality of teaching. Due to the different questions, this last questionnaire is 
uncomparable with those of the students. Therefore, we cannot explore one of the former research hypothesis concerning the assessment of the satisfaction gap between the "provider" and the "beneficiaries" of the teaching services. The questionnaires apply a 4-item Likert scale (definitely "no"; more "no" than "yes"; more "yes" than "no"; definitely "yes").

\section{Results - The statistical analysis}

We analyzed the data of 64.099 questionnaires completed by the students attending the academic courses belonging to the Health group, namely Pharmacy, Dentistry, Medical science, Veterinary Medicine. The remaining three scientific groups are: Science, Liberal Arts and Social, for a population of 189.698 questionnaires collected in the academic year 2013-2014. The questionnaires of the following academic year aren't still available but a systematic evaluation of them has been planned as it's considered of great interest for the governance of the University.

The analyzed questionnaires are related to 26 courses, each lasting a different period of time: the $38,6 \%$ of them belong to three years courses (L2), the $2 \%$ come from the following two years courses that are needed to complete the academic career started in L2 (called LM), the 13,8\% from the five years courses (in particular Dentistry, Veterinary Medicine and Pharmacy) and the last $45,7 \%$ is represented by the two six year-courses of Medicine, one of which is in English.

Through a descriptive analysis we obtain a first overview on student satisfaction, under the degree level variable and we find very high percentages of positive judgments (about $80 \%$ or more) in each question, either for students attending a three years course or a five/six years course, as we expected (Figure 1). In fact, these students have to pass a selection to enroll in each of the courses of the Health group and, due to this selection, the cohorts are composed by a low number of students, so positively influencing the "teaching climate".

The other possible stratification variable, the percentage of lesson attended, can't be included in the model because in Italian Universities the students enrolled in the courses of the health group have to attend more than $75 \%$ of the lessons otherwise they can't do their exams.

Then, in order to reduce the starting set of variables to the most significant ones, we adopt a multivariate statistical model. In particular, we run a Principal Component Analysis with PROMAX rotation and a backward procedure as follows:

(1) in the first step we consider all the eleven questions;

(2) in the second step we remove the questions with lower values and run PCA again;

(3) in the third step we obtain a measurement of the overall satisfaction.

As shown in Table 2, in the model with 11 questions the first component explains only the $58 \%$ of the variance (Keiser Meyer Olkin test $=0,949$ ). Therefore, we remove the questions q1, q2, q4, q5, q8, q11 since they seem to be poorly related to quality of teaching. Then we run a PCA on the new set of five variables and the percentage of explained variance increases at $73 \%$ (Keiser Meyer Olkin test $=0,874$, Table 3 ).

The obtained set of questions can be considered more reliable; it leads us to point out the «core» variables defining the overall satisfaction according to the students of the University of Bari. The quality of teaching seems to be related to what we can call the "tangible aspects" for a student: teaching materials (Q3), interesting lessons (Q6), teacher clearness (Q7), topics consistence with the statements on the website of the course of study (Q9), teacher availability for additional explanations (Q10). 
About the Satisfaction of the Students Attending the Health area Academic

Courses of the University of Bari

Q1 - Was the possessed prior knowledge sufficient for an understanding of the matters stated in the final exam?

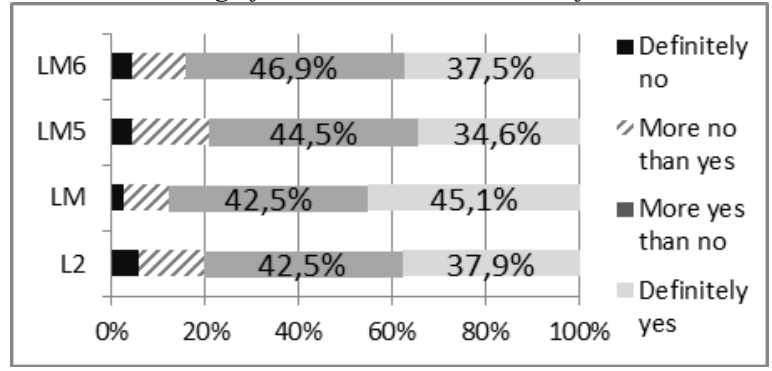

Q5-Are the unwinding times of lectures, tutorials and any other educational activities respected?

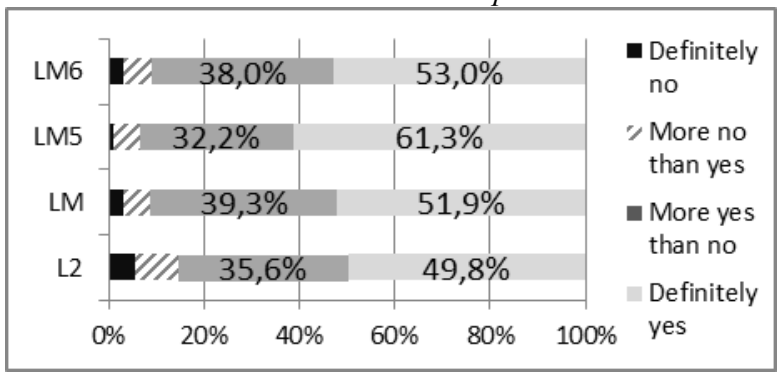

Q7 - Does the teacher set out the arguments in a clear way?

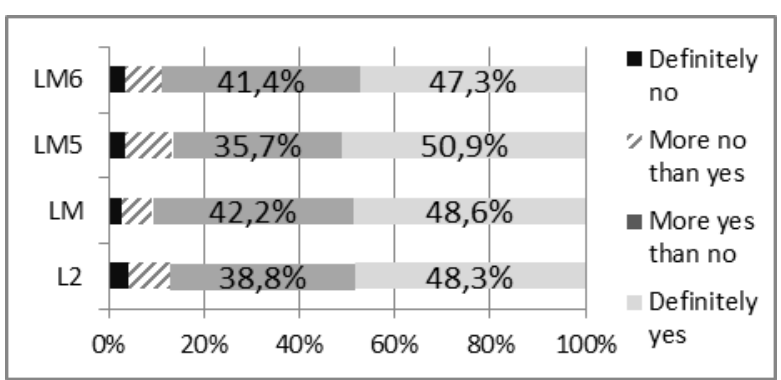

Q9 - Was the teaching carried out consistently with the statements on the website of the course?

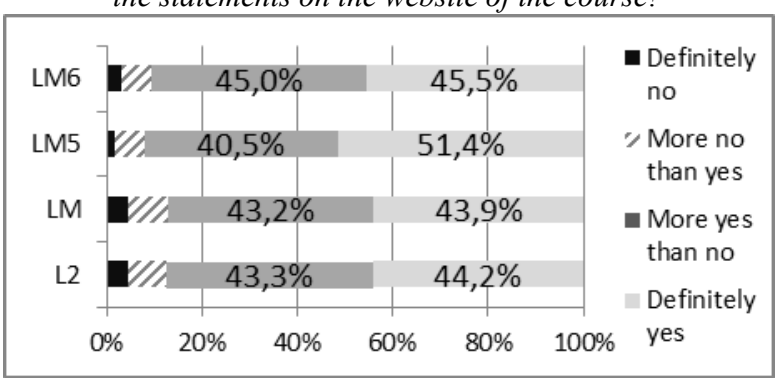

Q2 - Is the load of study required proportional to the assigned credits?

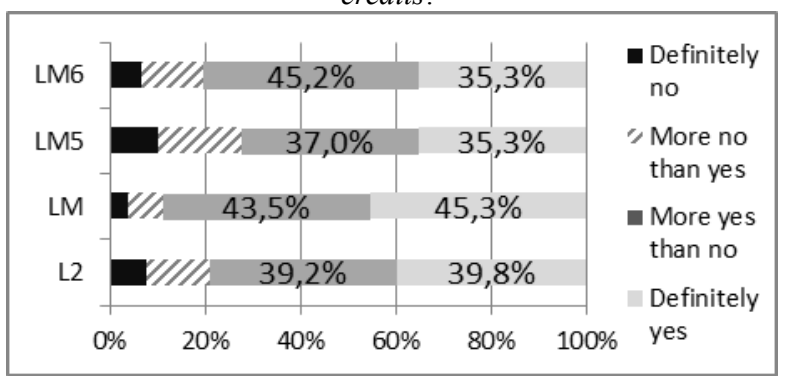

Q4 - Were the examination methods clearly defined?

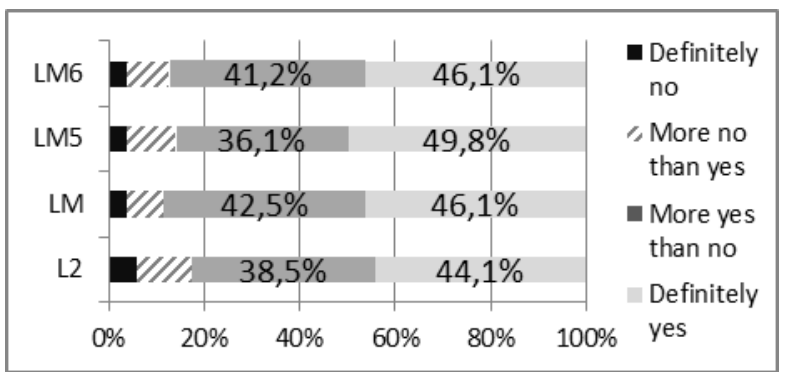

Q8 - Are the supplementary activities (exercises, tutorials, workshops), useful for learning the subject?

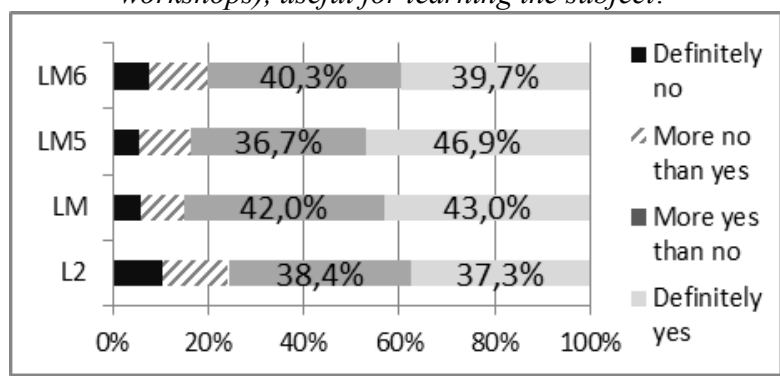

Q10 - Is the teacher available for clarification and explanations?

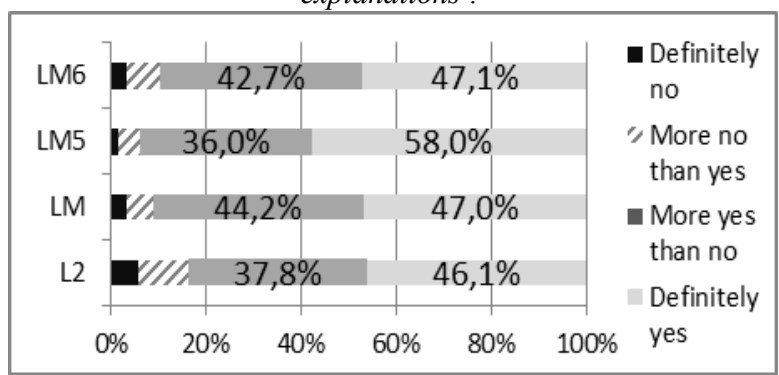

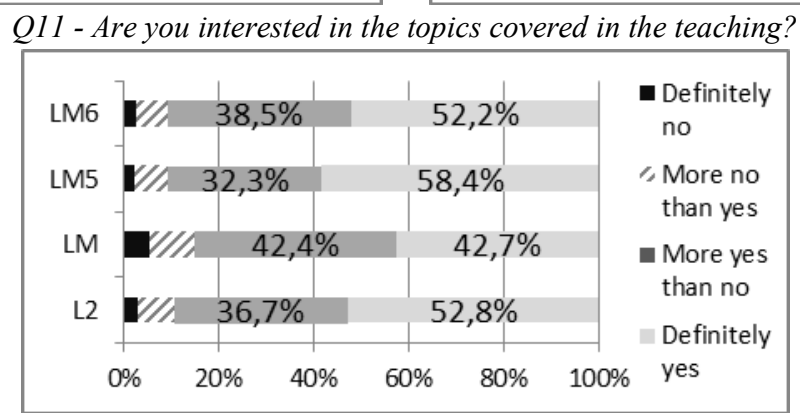

Figure 1. Students satisfaction in the eleven questions of the ANVUR questionnaire (p-value $=000$ ) 
Table 2

Percentage of explained variance and communality in the 11 questions model

\begin{tabular}{|c|c|c|c|c|c|c|c|c|c|}
\hline \multirow[b]{2}{*}{ Component } & \multicolumn{3}{|c|}{ Initial eigenvalues } & \multicolumn{3}{|c|}{ Not rotated factor loans } & \multicolumn{3}{|c|}{ Communality } \\
\hline & Total & $\begin{array}{l}\% \\
\text { variance }\end{array}$ & $\begin{array}{l}\text { of } \% \\
\quad \text { accumulated }\end{array}$ & Total & $\begin{array}{l}\% \\
\text { variance }\end{array}$ & $\begin{array}{l}\% \\
\text { accumulated }\end{array}$ & Questions & Initial & Extraction \\
\hline 1 & 6,382 & 58,018 & 58,018 & 6,382 & 58,018 & 58,018 & Q1 & 1,000 & ,397 \\
\hline 2 &, 854 & 7,759 & 65,777 & & & & Q2 & 1,000 & ,429 \\
\hline 3 & 694 & 6,307 & 72,084 & & & & Q3 & 1,000 & ,643 \\
\hline 4 &, 541 & 4,915 & 76,999 & & & & Q4 & 1,000 &, 576 \\
\hline 5 & ,494 & 4,492 & 81,490 & & & & Q5 & 1,000 &, 563 \\
\hline 6 & ,433 & 3,941 & 85,431 & & & & Q6 & 1,000 & ,718 \\
\hline 7 & ,415 & 3,773 & 89,204 & & & & Q7 & 1,000 & ,705 \\
\hline 8 & ,351 & 3,187 & 92,391 & & & & Q8 & 1,000 &, 575 \\
\hline 9 &, 342 & 3,113 & 95,504 & & & & Q9 & 1,000 & ,714 \\
\hline 10 & ,293 & 2,667 & 98,172 & & & & Q10 & 1,000 & ,667 \\
\hline 11 & ,201 & 1,828 & 100,000 & & & & Q11 & 1,000 & ,395 \\
\hline
\end{tabular}

Extraction method: Principal Component Analysis.

Table 3

Percentage of explained variance and communality in the 5 questions model

\begin{tabular}{|c|c|c|c|c|c|c|c|c|c|}
\hline \multirow[b]{2}{*}{ Component } & \multicolumn{3}{|c|}{ Initial eigenvalues } & \multicolumn{3}{|c|}{ Not rotated factor loans } & \multicolumn{3}{|c|}{ Communality } \\
\hline & Total & $\begin{array}{l}\% \\
\text { variance }\end{array}$ & $\begin{array}{l}\text { of } \% \\
\quad \text { accumulated }\end{array}$ & Total & $\begin{array}{l}\% \% \\
\text { variance }\end{array}$ & $\begin{array}{l}\% \% \\
\text { accumulated }\end{array}$ & Questions & Initial & Extraction \\
\hline 1 & 3,648 & 72,961 & 72,961 & 3,648 & 72,961 & 72,961 & Q3 & 1,000 & 650 \\
\hline 2 & ,439 & 8,781 & 81,742 & & & & Q6 & 1,000 &, 772 \\
\hline 3 & ,400 & 8,002 & 89,744 & & & & Q7 & 1,000 &, 774 \\
\hline 4 & ,305 & 6,107 & 95,850 & & & & Q9 & 1,000 &, 743 \\
\hline 5 & 207 & 4,150 & 100,000 & & & & Q10 & 1,000 &, 711 \\
\hline
\end{tabular}

Extraction method: Principal Component Analysis.

On the other side, we could suppose that the students consider some questions as «empty» questions if related to the quality dimension, for example Q11"Are you interested in the topics covered in the teaching/subject?", Q1 "Was the possessed prior knowledge sufficient for an understanding of the matters stated in the final examination?", Q4 "Were the examination methods defined clearly?", or that they consider them as exogenous variables. For example, they don't believe they could have a positive influence on the reduction of the teaching "load" in terms of subject/topics to be studied, as asked by Q2 "Is the load of study required proportional to the assigned credits?".

Precious information for the academic course responsible come from the students suggestions (Table 4). If we put them in a decreasing order, the highest frequency belongs to the reduction of the teaching load in terms of study effort $(60,7 \%)$, to be read along with the introduction of intermediate exams $(49,5 \%)$, followed by the exigence of a preparatory strengthening of the basic knowledge before starting the official course $(52,3 \%)$ and of an improvement of the quality of teaching materials $(50,4 \%)$, better if delivered in advance $(48,1 \%)$. The students acknowledge the added value brought by the support activities $(47,5 \%)$ but, since almost the totality of them don't work during their academic experience, they are not interested in possible evening teachings. 
Table 4

Suggestions from the students of the University of Bari to improve the quality of teaching in the courses of Health area

\begin{tabular}{lll}
\hline Suggestions & Number of responses & $\begin{array}{l}\text { \% on the total of } \\
\text { questionnaires }\end{array}$ \\
\hline Lighten the teaching load & 38916 & 60,7 \\
Provide more basic knowledge & 33508 & 52,3 \\
Improving the quality of teaching materials & 32335 & 50,4 \\
Insert the intermediate exams & 31726 & 49,5 \\
Provide course materials in advance & 30829 & 48,1 \\
Increasing the educational support activities & 30479 & 47,5 \\
Improve coordination with other teachings & 22730 & 35,5 \\
Delete the program topics already covered in other teachings & 22148 & 34,6 \\
Activate evening teachings & 3699 & 5,8 \\
\hline
\end{tabular}

\section{Conclusions}

The systematic survey Opinione degli studenti aims at measuring the students perception of the teaching quality at the University. It has been conceived as a national standardized survey which will allow, among other goals, the Ministry of Research and education to organize a database useful for the evaluation of the quality of teaching in the Italian Universities and, probably, in the future, for the allocations of financial resources. At a University or Department level, in the internal governance process, the results of the survey may represent precious information for improving the quality of the courses, either on the issues strictly related to teaching or on the organizational and logistic aspects. Anyway, a certain caution in handling the data collected through this survey is essential because we have no evidence that the students expressed their judgements with the awareness of being a part of an awkward evaluation process with important outcomes. Moreover, the fear of lack of privacy could have affected the judgments expressed by the students, as their answers look too "compliant"? Another important issue to be considered is that the Survey supplies a measure of student opinion, not a direct measure of quality and therefore it might be influenced by a variety of biases, first of all the effect of prior expectations. A further development of this first analysis is to deal with a set of indexes which can measure the reliability of the data, so that they can be useful in sustaining the decisional process as they could be used as input in the evaluation models, for example, in the allocation of internal funds. To move from solid foundations, a comparison with other Italian Universities' experience in this survey would be very interesting. Looking at the present work, the results of our analysis show a high level of the overall satisfaction of the students of University of Bari enrolled in the courses of the health area, being completely aligned with their colleagues of the Liberal Arts, Scientific and Social areas (D'Uggento, Manca and Girone, 2016). The quality of teaching seems to be to be related to what we called the "tangible aspects" for a student: teaching materials, interesting lessons, teacher clearness, topics consistence with the statements on the website of the course of study, teacher availability for additional explanations. In the next years, one of the challenges for the academic courses planning responsibles could be the adoption of initiatives aimed at reaching the $100 \%$ of satisfied students. 
About the Satisfaction of the Students Attending the Health area Academic

Courses of the University of Bari

\section{References}

D’Uggento A. M., Manca F., Girone F. (2016). Student Satisfaction and Quality of Education Services in The University of Bari in Notes and abstract, Proceedings of the international conference Data Science \& Social Research, 17-19 February 2016, D. Trezza, C.C. De Falco, F. Manzo Editore, Napoli.

Fabbris, L. (2012). Indicators of Higher Education Effectiveness. McGraw-Hill, Milano.

Fabbris, L. (1997). Statistica multivariata. Analisi esplorativa dei dati. McGraw-Hill, Milano. 